\title{
HIV infection epidemiology: a change of scenery
}

\author{
Maria J. Vivancos ${ }^{1} \cdot$ Javier Martínez-Sanz ${ }^{1} \cdot$ Santiago Moreno ${ }^{1}[$
}

Received: 15 November 2018 / Accepted: 28 November 2018 / Published online: 11 December 2018

(c) European Geriatric Medicine Society 2018

\begin{abstract}
Combination antiretroviral therapy has completely changed the landscape of HIV infection through the control of viral replication of the virus, the restoration of the immune system damage, and the reduction of the complications associated with immunodeficiency. As a consequence, the average age of people living with HIV has been increasing progressively, with a high proportion of diagnosed, as well as newly diagnosed, HIV-infected patients being older than 50 years throughout the world. With the longer life expectancy, characteristics commonly observed in aging are occurring in people with longterm HIV infection, including multiple chronic diseases, changes in cognitive and physical abilities, and the use of multiple medications. HIV-related specific factors, as well as a higher prevalence of environmental, classical factors, increase the risk of comorbidities in the aging HIV-infected population. A close collaboration between different specialists (HIV specialists, geriatricians, primary care physicians, and other specialists) is required to manage the clinical problems that older HIVinfected patients may present.
\end{abstract}

Keywords HIV · Aging · Comorbidities · Immunesenescence · Polypharmacy

\section{Introduction}

The history of HIV infection is a success story of modern medicine. In 1981, an epidemic began caused by an unknown infectious agent that would have a worldwide health and social impact that was far from being suspected. The disease had among its most salient features the involvement especially of young people, with extreme suffering and with a very high, almost uniform mortality. From the point of view of healthcare, there was little more to do than to diagnose and treat the opportunistic events, and to provide palliative care throughout the disease. No measure could substantially alter the course of the disease and the early deaths.

This dramatic vision of the disease was experienced for more than a decade until the great change in the mid-1990s of the last century. The introduction of combination antiretroviral treatment (ART) effectively controlled the replication

Santiago Moreno

smguillen@salud.madrid.org

1 Department of Infectious Diseases, Hospital Ramón y Cajal, Instituto Ramón y Cajal de Investigación Sanitaria (IRYCIS), Alcalá de Henares University, Carretera de Colmenar, Km 9.100, 28034 Madrid, Spain of the virus and thereby restored the immune system and reduced the complications associated with immunodeficiency. The immediate and visible consequences were the decrease in morbidity and mortality. The HIV infection went from being a disease of progressive and accelerated course towards death, to be a manageable disease, of nonfatal chronic evolution. Progressively, as the indications for antiretroviral treatment have been expanded and the available drugs have improved, the expected survival has been increasing to become in many cases similar to that of the population not infected with HIV.

These very positive changes in the management of HIV infection have brought about some logical consequences. The average age of people living with HIV has been increasing progressively and the median age of patients seen in clinic now exceeds 50 years [1,2]. Clinically we are witnessing two concomitant facts: on the one hand, the practical disappearance of opportunistic problems related to HIV and, on the other hand, the emergence of health problems related to age. There is no doubt that there has been a change in the scenario of HIV infection in practically the entire world [3].

The objective of this work is to present an overview of the epidemiological changes that have affected the HIV-infected population with the increase in age and the clinical problems that present as a consequence at present. 


\section{Epidemiology of the aging HIV-infected population}

The global proportion of people living with HIV (PLWH) on antiretroviral therapy (ART) has increased from $12 \%$ to $46 \%$ in the past 10 years [4]. Using information data from European and North American HIV cohorts, between 1996 and 2010, life expectancy in 20-year-old patients starting ART increased 9 years in women and 10 years in men [5]. Moreover, according to UNAIDS out of 36.7 million of PLWH in 2015, 5.8 million were aged 50 years and older [6]. Therefore, aging with HIV infection could be largely attributable to the expansion of access to treatment and the advances in the management of the HIV infection.

\section{Prevalence of adults aged 50 years and older living with diagnosed HIV}

The prevalence rate of adults aged 50 years and older living with diagnosed HIV infection has increased consistently in all regions at varying rates since 2007. Western/Central Europe and North America have the highest percentage of people living with HIV (PLWH) over 50 years (30\%), while regions of Sub-Saharan Africa have the lowest rates (7.6\%) [7].

The situation in Western/Central Europe is illustrated by studies from different countries in the region. According to the data from the Danish HIV Cohort Study, the median survival time from age 50 years among PLWH had increased from 11.8 years during 1996-1999 to 22.8 years from 2006-2014 [8]. Similar results are found using data from the UK Collaborative HIV Cohort (UK CHIC) Study, reporting that life expectancy of PLWH at age 20 had increased from 30.0 to 45.8 years from 1996-1999 to 2006-2008 and overall life expectancy was 39.5 for men and 50.2 years for women [9]. In 2004, in Spain, there were $6.8 \%$ of women and $9.6 \%$ of men living with HIV aged 50 years or older (Fig. 1). However, in 2014 this percentage increases up to $21.4 \%$ and 26.2 , respectively [10].

In the United States, the number of older adults living with diagnosed HIV infection increased from 329,152 to 454,685 between 2011 and 2015, with the largest percentage of them aged 50-54 years (38\%), followed by those aged 55-59 (29\%) in 2015 [11]. This rise is clearly demonstrated by data from San Francisco and New York City, both important epicenters of the AIDS epidemic. Whereas in 1990, the percentage of people living with HIV who were over the age of 50 years was $10 \%$ by 2010 it had reached $50 \%$ [12].

Interestingly, in the United States, African Americans account for the largest percentage of older PLWH (39\%), follow by whites (37\%). Among the older males with HIV, $64 \%$ of infections are attributed to sexual contact with other men, whereas in older females $70 \%$ of infections are attributed to heterosexual contact [11].

With respect to other regions, the average age of men living with HIV in Australia increased from 45 years in 2007 to 49 years, while the average age of female has increased from 40 years in 2007 to 44 years in 2017 [13]. Despite the lack of information about aging with HIV in Africa, it is known that the number of people living with HIV in low- and middle-income countries aged 50 or older is growing, representing $12 \%$ of all adult people living with HIV in 2013. The trend is similar across subSaharan Africa, where recent modeling projected that the total number of people living with HIV aged 50 or older will nearly triple in the coming years [6].
Fig. 1 Age distribution by calendar year in the Cohort of the Spanish Research Network (CoRIS) from 2004 to 2014. The proportion of patients aged $\geq 50$ years increased from $8.8 \%$ to $21.2 \%$ from 2004 to 2014

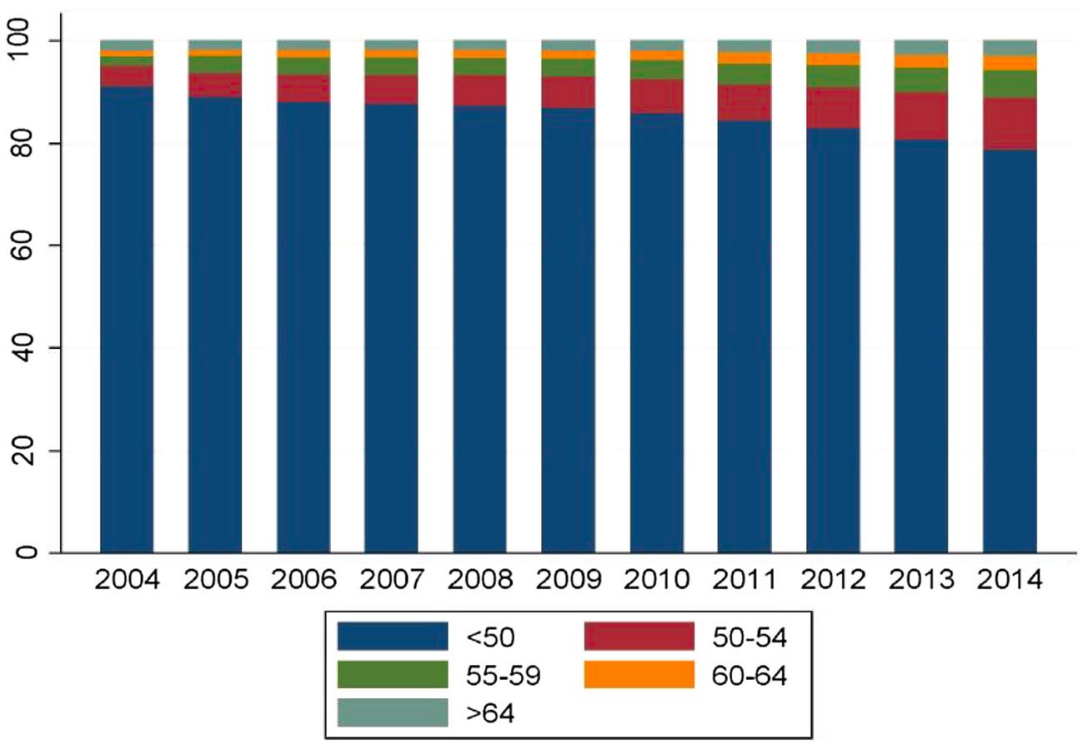




\section{Incidence of new HIV infection in those aged more than $\mathbf{5 0}$ years}

In addition to the augmented life expectancy of PLWH, there have also been continued new HIV diagnoses and new HIV infections in those aged more than 50 years.

Within Europe, older adults with 50 years and above comprised $39 \%$ of the population and $17 \%$ of new HIV diagnoses in 2015. In six countries (Finland, France, Malta, Netherlands, Norway, and Portugal), older adults comprised more than $20 \%$ of those newly diagnosed with HIV. Of note, in 2015 , the proportion of cases diagnosed at or below 350 $\mathrm{CD} 4$ cells per $\mathrm{mm}^{3}$ increased with age and $63 \%$ of persons aged 50 or older were diagnosed with HIV at or below 350 cells per $\mathrm{mm}^{3}$ [14].

According to Public Health England, the proportion of people newly diagnosed with HIV over the age of 50 has increased from $9.2 \%$ in 2005 to $18.6 \%$ in 2014 [15]. The changing age distribution of new HIV-infected individuals over time was also studied by a Dutch group [16]. They described in 1996 that around 14\% of the patients in care were younger than 30 years of age, whereas $11 \%$ were 50 years or older. In 2016, these proportions were $7 \%$ and $46 \%$, respectively, while $16 \%$ of patients in care were 60 years of age or older.

In Canada in 2007, one in 10 new diagnoses of HIV was in people aged 50 years and above $(10 \%)$ whereas by 2013 , that number increased to one in five (20\%) [17].

In the United States, patients aged 50 and older accounted for 17\% (6812) of the 39,782 new HIV diagnoses in 2016 and those aged 50 to 54 accounted for $43 \%$ (2959) of the new diagnoses among people aged 50 and older. Among people aged 50 and older, $49 \%$ of new HIV diagnoses in 2016 were among MSM and 42\% of all new HIV diagnoses in 2016 were blacks/African Americans. The rate for older males was 3 times the rate for older females. As described in European cohorts, older patients in the US often present with advanced infection, if not as AIDS presenters. However, from 2011 to 2015 late diagnosis of patients aged 50 and older in the US decreased from $42 \%$ to $35 \%$, respectively [11].

\section{Aging with HIV: trends and projections}

The increases in age are also expected to continue into the future. A model from The Netherlands predicted a median age of PLWH on ART of 56.6 years in 2030 with a proportion of patients aged 50 and older of $73 \%$ [18]. Simulations in Australia showed that by 2027, the highest proportion of diagnosed PLWH will be in the 55-59 ages. It has been calculated a projected life of 75 years old for HIV-positive men who have sex with men living in a developed country with access to care and assuming early diagnosis [19].
Importantly, in PLWH with virological and immunological response to ART estimated life expectancy has improved in recent years. However, life expectancy could be lower than that of the general population, depending on the geographic setting [20].

\section{Clinical aspects of aging with HIV}

With the longer life expectancy, characteristics commonly observed in aging are occurring in people with long-term HIV infection: multiple chronic diseases, changes in cognitive and physical abilities, and the use of multiple medications. For older people, sorting out the interplay between HIV, aging and the side effects of medications can be very difficult. The new challenge is the correct approach of these patients who require medical attention adapted to their needs.

\section{Prevalence of comorbidities in aging HIV-infected patients}

There is growing evidence that the prevalence of comorbidities and other age-related conditions (functional or neurocognitive disorders, geriatric syndromes, polypharmacy and social problems) is higher in the HIV-infected than in the non-infected population [21]. A large study from the Netherlands showed that $85 \%$ of people living with HIV were projected to have at least one comorbidity by 2030 , up from $28 \%$ in 2010 [18]. With the aging of the HIV-infected population, the burden of non-AIDS conditions (cardiovascular disease, hypertension, diabetes, bone fractures, neurocognitive impairment, cancer, kidney and liver disease) has been increasing steadily $[2,22,23]$. A recent analysis of the EuroSIDA study, in which a comparison of two cross-sectional cohorts of HIV-positive individuals was performed, showed that between 2006 and 2014 the population experienced an overall higher prevalence of non-AIDS comorbidities [24] (Fig. 2). It has been observed that polymorbidity develops approximately 10 years earlier than in HIV-uninfected individuals [22]. As a result of the previous, non-AIDS-related mortality has overtaken AIDS-related mortality as the leading cause of death in HIV-infected people with widespread access to antiretroviral therapy $[25,26]$.

Older patients living with HIV have numerous factors that can affect their quality of life, including comorbidity, physical and neurocognitive disabilities, social isolation, and stigma [27]. In a case-control study in San Diego, older HIV-positive patients were found to have worse physical and mental function and greater psychosocial stress than HIV negative patients [28]. Interventions focused on improving factors such as social support can improve the quality of life of aging HIV-positive patients. 


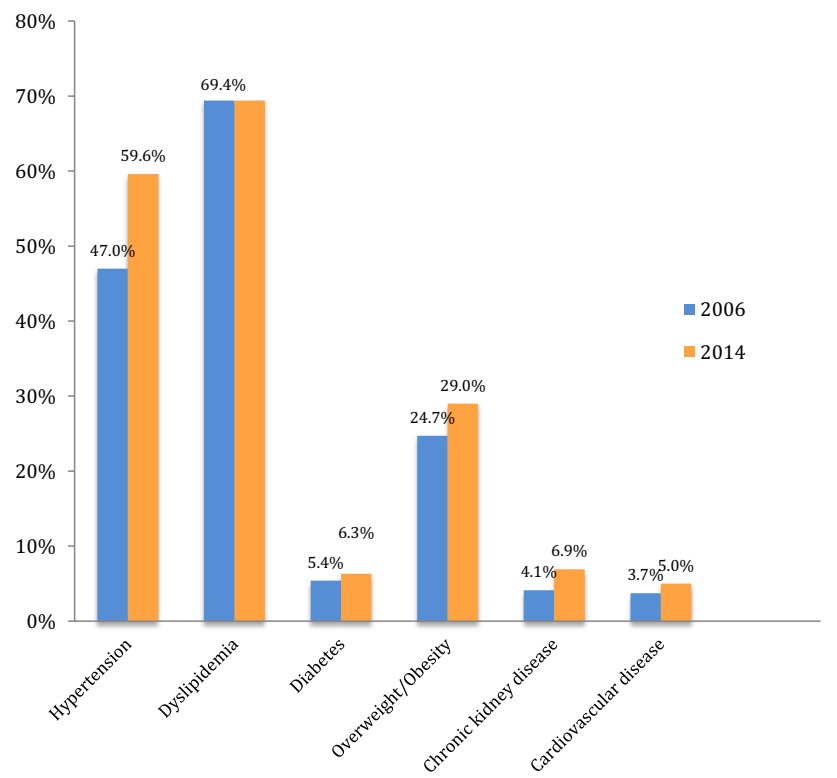

Fig. 2 Trends in comorbid conditions among patients with HIV infection. EuroSIDA cohort, 2006 vs. 2014. Adapted from Pelchen-Matthews et al. [24]

\section{Why are comorbidities increased in HIV infection?}

The reasons behind the increased risk for comorbidities in older patients infected with HIV are not well understood. HIV-mediated changes in the immune system lead to an alteration in $\mathrm{T}$ cell subtypes and $\mathrm{T}$-cell function ('immunosenescence') and an increase in levels of inflammatory cytokines and markers of immune activation, which result in an earlier onset of age-related chronic diseases and frailty. These changes manifest as poor response to vaccination, increased susceptibility to infection, and higher risk of cancer and CVD [29]. The presence of subclinical chronic inflammation has been related to a decrease in survival among HIV-infected individuals [30]. These changes to the immune system are similar to those seen in very old but otherwise healthy people [31]. HIV has been associated with many of the hallmarks of normal aging, including increased genetic instability, enhanced T-cell senescence, diminished naïve T-cell regeneration, and altered intracellular communication from deregulated nutrient sensing, heightened inflammation, and cytotoxic proteins [32, 33].

Some studies have shown that the level of HIV-associated inflammation decreases with effective ART, but remains high compared to people without HIV. The contribution of this residual inflammation to the development of non-AIDS-defining illnesses and mortality remains unclear, although an association between the presence of biomarkers (interleukin-6, soluble tumor necrosis factor receptor I and II, plasma kynurenine-to-tryptophan ratio, and D-dimer) with the occurrence of a non-AIDS-defining event has been reported [34].

However, the increased prevalence of comorbidity observed in older people living with HIV cannot be attributed entirely to HIV infection alone and is likely to represent an interaction between different factors, including different demographic characteristics and socioeconomic status, higher rates of traditional risk factors, co-infections and opportunistic infections, and exposure to antiretroviral treatment, along with the direct effect of the HIV infection itself [35].

\section{Management of aging HIV-infected patients}

This situation generates multiple clinical management problems in daily practice. A close collaboration between different specialists is required to manage the comorbidities that these patients present (HIV specialists, geriatricians, primary care physicians, and other specialists). The simultaneous use of multiple drugs for the management of these different conditions determines the appearance of polypharmacy, with the consequent risk of drug interactions and pharmacological toxicity. A recent study from the Multicenter AIDS Cohort investigated polypharmacy prevalence for non-HIV medications over a 12-year period among HIV-positive and -negative participants. Both groups had an increase in polypharmacy; however, HIV-positive status was associated with an increased likelihood of polypharmacy after adjusting for confounding variables [36]. In older patients, the selection of ART is difficult, due to reasons stated above: increased risk of toxicity and worsening of comorbidities (e.g., renal or bone disease secondary to tenofovir, possible increase in cardiovascular risk with abacavir, risk of drug interactions with enhanced protease or integrase inhibitors) [29]. Early and continuous antiretroviral therapy reduces the risk of most comorbidities, suggesting that age-accelerating effects by HIV infection may be reversible [37, 38].

\section{Compliance with ethical standards}

Conflict of interest MJ. Vivancos has received honoraria for the following: lectures and from AbbVie, Gilead Sciences, and ViiV Healthcare. She has also received travel grants from Gilead Sciences and ViiV Healthcare. J. Martínez Sanz declares no conflict of interest. Santiago Moreno has been involved in speaking activities and has received grants for research from Abbott, Boehringer\& Ingelheim, Bristol-Myers Squibb, Gilead, Glaxo Smith Kline, Janssen Cilag, Merck Sharp\&amp; Dohme, Pfizer, Roche, and Schering Plough.

Ethical approval This article does not contain any studies with human participants or animals performed by any of the authors. 


\section{References}

1. Bunting E, Rajkumar C, Fisher M (2014) The human immunodeficiency virus and ageing. Age Ageing 43:308-310

2. Brañas F, Berenguer J, Sánchez-Conde M, López-Bernaldo de Quirós JC, Miralles P, Cosín J et al (2008) The eldest of older adults living with HIV: response and adherence to highly active antiretroviral therapy. Am J Med 121:820-824

3. Centers for Disease Control and Prevention. HIV Surveillance Report, 2016; Vol. 28. Available at: https://www.cdc.gov/hiv/pdf/ library/reports/surveillance/cdc-hiv-surveillance-report-2016vol-28.pdf. Accessed 25 Oct 2018

4. Joint United Nations Programme on HIV/AIDS. Global AIDS update 2016. Geneva: UNAIDS. 2016. Available from http:// www.unaids.org/sites/default/files/media_asset/global-AIDSupdate-2016_en.pdf. Accessed 25 Oct 2018

5. Trickey A, May MT, Vehreschild JJ, Obel N, Gill MJ, Crane HM et al (2017) Survival of HIV-positive patients starting antiretroviral therapy between 1996 and 2013: a collaborative analysis of cohort studies. Lancet HIV 4:e349-e356

6. UNAIDS (2014) U. The gap report. Geneva, Switzerland. http:// files.unaids.org/en/media/unaids/contentassets/documents/unaid spublication/2014/UNAIDS_Gap_report_en.pdf. Accessed 25 Oct 2018

7. Joint United Nations Programme on HIV/AIDS (UNAIDS) (2013) Global report. UNAIDS report on the global AIDS epidemic. http://files.unaids.org/en/media/unaids/contentassets/ documents/epidemiology/2013/gr2013/UNAIDS_Global_Repor t_2013_en.pdf Accessed 25 Oct 2018

8. Rasmussen LD, May MT, Kronborg G, Larsen CS, Pedersen C, Gerstoft $\mathbf{J}$ et al (2015) Time trends for risk of severe age-related diseases in individuals with and without HIV infection in Denmark: a nationwide population-based cohort study. Lancet HIV 2:e288-e298

9. May MT, Gompels M, Delpech V, Porter K, Orkin C, Kegg S et al (2014) Impact on life expectancy of HIV-1 positive individuals of CD4+ cell count and viral load response to antiretroviral therapy. AIDS 28:1193

10. Alejos B, Hernando V, del Amo J, Rubio R, Montero M, Rivero $M$ et al (2016) Ageing and associated morbidity in HIV-positive persons in the Cohort of the Spanish AIDS Research Network (CoRIS). J Int AIDS Soc 19(Suppl 5):141-142

11. Mitsch A, Singh S, Li J, Balaji A, Linley L, Selik R (2018) Ageassociated trends in diagnosis and prevalence of infection with HIV among men who have sex with men-United States, 20082016. MMWR Morb Mortal Wkly Rep 67:1025-1031

12. New York City Department of Health and Mental Hygiene (2012) New York City HIV/AIDS annual surveillance statistics 2010. https://www1.nyc.gov/site/doh/data/data-sets/hiv-aids-annua 1-surveillance-statistics.page. Accessed 25 Oct 2018

13. Bretaña N, Gray R, Law M, Guy R (2018) Aging of the HIV population in Australia: a modeling study. J Acquir Immune Defic Syn. https://doi.org/10.1097/QAI.0000000000001870

14. World Health Organization (2015) HIV/AIDS surveillance in Europa 2015. Surveillance Report. 2015 Available from: [Internet]. http://www.euro.who.int/_data/assets/pdf_file/0019/32437 0/HIV-AIDS-surveillance-Europe-2015.pdf?ua=1. Accessed 25 Oct 2018

15. Public Health England (2018) Trends in new HIV diagnoses and people receiving HIV-related care in the United Kingdom: data to the end of December 2017. https://assets.publishing.servi ce.gov.uk/government/uploads/system/uploads/attachment_data/ file/738222/hpr3218_hiv17_v2.pdf. Accessed 25 Oct 2018

16. Report HIVM (2018) HIV monitoring report human immunodeficiency virus (HIV) infection in the Netherlands [Internet]. https
://www.hiv-monitoring.nl/files/6614/7999/7485/HIV_Monitoring Report_2016_24_Nov.pdf. Accessed 25 Oct 2018

17. Information C. National Coordinating Committee on HIV and Aging HIV and older adults - media primer key messages CALL TO ACTION ! 1999; Available from: http://www.realizecanada. org/wp-content/uploads/HIV-and-Aging-Media-Primer-Nov2015-FINAL.pdf. Accessed 25 Oct 2018

18. Smit M, Brinkman K, Geerlings S, Smit C, Thyagarajan K, van Sighem A et al (2015) Future challenges for clinical care of an ageing population infected with HIV: a modelling study. Lancet Infect Dis 15:810-818

19. Nakagawa F, Lodwick RK, Smith CJ, Smith R, Cambiano V, Lundgren JD et al (2012) Projected life expectancy of people with HIV according to timing of diagnosis. AIDS 26:335-343

20. Sabin CA, Reiss P (2017) Epidemiology of ageing with HIV: what can we learn from cohorts? AIDS 2017(31):S121-S128

21. Negredo E, Back D, Blanco JR, Blanco J, Erlandson KM, Garolera $M$ et al (2017) Aging in HIV-infected subjects: a new scenario and a new view. Biomed Res Int 2017:1-9

22. Guaraldi G, Orlando G, Zona S, Menozzi M, Carli F, Garlassi E et al (2011) Premature age-related comorbidities among HIVinfected persons compared with the general population. Clin Infect Dis 53:1120-1126

23. Goulet JL, Fultz SL, Rimland D, Butt A, Gibert C, RodriguezBarradas $\mathrm{M}$ et al (2007) Do patterns of comorbidity vary by HIV status, age, and HIV severity? Clin Infect Dis 45:1593-1601

24. Pelchen-Matthews A, Ryom L, Borges ÁH, Edwards S, Duvivier C, Stephan C et al (2018) Aging and the evolution of comorbidities among HIV-positive individuals in a European cohort. AIDS. 32:2405-2416

25. Alejos B, Hernando V, López-Aldeguer J, Segura F, Oteo JA, Rubio R et al (2014) Overall and cause-specific mortality in HIVpositive subjects compared to the general population. J Int AIDS Soc 17:19711

26. Miller CJ, Baker JV, Bormann AM, Erlandson KM, Huppler Hullsiek K, Justice AC et al (2014) Adjudicated morbidity and mortality outcomes by age among individuals with HIV infection on suppressive antiretroviral therapy. PLoS One 9:e95061

27. Wing EJ (2016) HIV and aging. Int J Infect Dis 53:61-68

28. Moore RC, Moore DJ, Thompson WK, Vahia IV, Grant I, Jeste DV (2013) A case-controlled study of successful aging in older HIV-infected adults. J Clin Psychiatry 74:e417-e423

29. Escota GV, O'Halloran JA, Powderly WG, Presti RM (2018) Understanding mechanisms to promote successful aging in persons living with HIV. Int J Infect Dis 66:56-64

30. Grund B, Baker JV, Deeks SG, Wolfson J, Wentworth D, CozziLepri A et al (2016) Relevance of interleukin-6 and D-dimer for serious non-AIDS morbidity and death among HIV-positive adults on suppressive antiretroviral therapy. PLoS One 11:e0155100

31. Deeks SG (2011) HIV infection, inflammation, immunosenescence, and aging. Annu Rev Med 62:141-155

32. Van Epps P, Kalayjian RC (2017) Human immunodeficiency virus and aging in the Era of effective antiretroviral therapy. Infect Dis Clin N Am 31:791-810

33. López-Otín C, Blasco MA, Partridge L, Serrano M, Kroemer G (2013) The hallmarks of aging. Cell 153:1194-1217

34. Tenorio AR, Zheng Y, Bosch RJ, Krishnan S, Rodriguez B, Hunt PW et al (2014) Soluble markers of inflammation and coagulation but not T-cell activation predict non-AIDS-defining morbid events during suppressive antiretroviral treatment. J Infect Dis 210:1248-1259

35. Burch LS, Smith CJ, Anderson J, Sherr L, Rodger AJ, O'Connell $\mathrm{R}$ et al (2016) Socioeconomic status and treatment outcomes for individuals with HIV on antiretroviral treatment in the UK: cross-sectional and longitudinal analyses. Lancet Public Health 1:e26-e36 
36. Ware D, Palella FJ, Chew KW, Friedman MR, D'Souza G, Ho K et al (2018) Prevalence and trends of polypharmacy among HIVpositive and -negative men in the Multicenter AIDS Cohort Study from 2004 to 2016. PLoS One 13:e0203890

37. The INSIGHT START Study Group (2015) Initiation of antiretroviral therapy in early asymptomatic HIV infection. N Engl J Med 373:795-807
38. Borges ÁH, Neuhaus J, Babiker AG, Henry K, Jain MK, Palfreeman A et al (2016) Immediate Antiretroviral therapy reduces risk of infection-related cancer during early HIV infection. Clin Infect Dis 63:1668-1676 